\title{
Arquitetura Pedagógica de Resolução de Problemas em um Jogo Digital ${ }^{1}$
}

\author{
Muriel Lago², Rosane Aragón ${ }^{3}$ \\ ${ }^{2}$ Mestranda em Educação (UFRGS) - CEP 95710-000 - Bento Gonçalves - RS - \\ Brasil \\ ${ }^{3}$ Programa de Pós-Graduação em Educação - Universidade Federal do Rio Grande do
} Sul (UFRGS) - CEP 90046-900 - Porto Alegre - RS - Brasil

muriellago@yahoo.com.br, rosane.aragon@gmail.com

\begin{abstract}
In this paper we present and discuss the application of a problem solving pedagogical architecture supported by a digital game. The proposal, developed through challenges and the use of active methodology, allowed the subjects a protagonist posture in the search for solutions and allowed to analyze their learning pathways by discovery. The results, considering the studies by Piaget (1985) and Inhelder e Cellérier (1996), show that the pedagogical architecture was relevant as it provoked cognitive imbalances, offering opportunities for students to resignify their behaviors, overcoming their difficulties and building new ways of thinking.
\end{abstract}

Resumo: Neste artigo apresentamos e discutimos a aplicação de uma arquitetura pedagógica de resolução de problemas apoiada em um jogo digital. A proposta, desenvolvida mediante desafios e uso de metodologia ativa, possibilitou aos sujeitos uma postura protagonista na busca de soluções e permitiu analisar os seus percursos de aprendizagem por descobertas. Os resultados, tendo em vista os estudos de Piaget (1985) e Inhelder e Cellérier (1996), evidenciam que a arquitetura pedagógica foi relevante na medida em que provocou desequilíbrios cognitivos, oferecendo oportunidades para que os alunos pudessem ressignificar suas condutas, ultrapassando suas dificuldades e construindo novas formas de pensar.

\section{Introdução}

Atualmente, tornam-se imprescindíveis os diálogos que buscam intensificar a inserção das Tecnologias Digitais na Educação. Apesar do avanço com relação ao Ensino Superior a distância, as Tecnologias parecem estar ainda um pouco distantes do contexto escolar da Educação Básica e, muitas vezes, desvinculadas de uma proposta ativa de aprendizagem.

\footnotetext{
${ }^{1} \mathrm{O}$ presente artigo está vinculado à dissertação de Mestrado de Muriel Lago, desenvolvida no Curso de Pós-Graduação em Educação da Universidade Federal do Rio Grande do Sul (UFRGS), sob a orientação da Prof ${ }^{a}$. Dr ${ }^{\text {a }}$. Rosane Aragón.
} 
Nesse contexto, entendemos que a inserção das Tecnologias Digitais na educação não acontece de uma forma mágica, é preciso planejamento e objetivos definidos para que ela não se torne apenas um meio, mas, sim, que proporcione o empoderamento de toda uma sociedade.

Desta forma, parece-nos relevante considerar as contribuições que as arquiteturas pedagógicas trazem ao cenário educacional. De acordo com Carvalho, Nevado e Menezes (2005, p.39) as arquiteturas pedagógicas compreendem, em seus pressupostos curriculares, "pedagogias abertas capazes de acolher didáticas flexíveis, maleáveis, adaptáveis a diferentes enfoques temáticos".

Nesse mesmo cenário, podemos acompanhar no cotidiano escolar a facilidade e entusiasmo com que os alunos se relacionam com as Tecnologias Digitais, divertindo-se com jogos digitais, seja em computadores, tablets ou outros dispositivos. Savi e Ubricht (2008) mencionam alguns benefícios que os jogos digitais trazem ao contexto educacional, dentre os quais, destacamos seu aspecto motivador, a possibilidade de desenvolvimento de habilidades cognitivas e o aprendizado por descobertas.

Portanto, imbricadas aos jogos digitais, entendemos que o uso de arquiteturas pedagógicas objetiva a transformação do espaço destinado ao ensino em um espaço sedutor, que motive o aluno na busca por seus conhecimentos e provoque o mesmo a superar seus desafios, instigando a curiosidade, para que sejam modificadas as formas de conhecer e aprender dos sujeitos.

Tendo em vista tais considerações, o presente artigo apresenta uma experiência de uso de uma arquitetura pedagógica em um jogo digital, articulando portanto, uma metodologia ativa, na forma de propostas de resolução de problemas, na qual os estudantes possam construir seus conhecimentos de forma autônoma, valendo-se também, das possibilidades que os jogos digitais podem trazem ao ensino.

\section{Arquiteturas Pedagógicas}

De acordo com Aragon, Menezes, Ziede e Charczuk (2013, p.6), "as Arquiteturas Pedagógicas (AP) são definidas como "suportes estruturantes" para a aprendizagem que combinam epistemologia e concepção pedagógica, com o aparato tecnológico, dentro de uma visão ecossistêmica.

Deste modo compreendemos que as arquiteturas pedagógicas evidenciam um novo olhar para a inserção das tecnologias no contexto escolar, na medida em que buscam transformar a ideia de uso da tecnologia como um simples meio ou ferramenta para inovar o ensino. Ao contrário, as arquiteturas pedagógicas inserem-se numa perspectiva de ecologia cognitiva onde o sujeito-aluno se constrói em meio à cultura tecnológica, ao mesmo tempo em que, ele, enquanto cultura, modifica e constitui a tecnologia.

\section{Arquiteturas Pedagógicas de Resolução de Problemas}

Tendo em vista o conceito de arquiteturas pedagógicas, entendemos que as arquiteturas pedagógicas de resolução de problemas, produzem um processo em espiral, uma construção, uma dinâmica, na qual indivíduo e cultura vão se constituindo. Assim, surgem novas formas de pensar, graças à abertura de possibilidades provenientes dessa relação e, com isso, modificam-se os modos de conhecer e de aprender dos sujeitos. 
VIII Congresso Brasileiro de Informática na Educação (CBIE 2019)

Anais dos Workshops do VIII Congresso Brasileiro de Informática na Educação (WCBIE 2019)

Considerando o papel do aluno nesse processo, Nevado, Dalpiaz e Menezes (2009) explicam que as arquiteturas pedagógicas de resolução de problemas, inserem o aluno em um ambiente ativo. Este, ao se deparar com uma situação-problema é capaz de estabelecer e reconhecer semelhanças, distâncias, proximidades com vivências anteriores. Nesse caso, tem a possibilidade de apoiar-se em uma situação-problema anterior e tomála como ponto de partida e suporte para a compreensão e busca de objetivos na situação atual.

Portanto, entendemos que, fundamentadas numa perspectiva ecológica as arquiteturas pedagógicas de resolução de problemas, devem privilegiar, conforme Nevado, Dalpiaz e Menezes (p.1654) nos explicam,

(...) atividades interativas e intervenções problematizadoras, que atuam de forma a provocar, por um lado, desequilíbrios cognitivos e, por outro, suportes para as reconstruções. Dessa forma, as arquiteturas solicitam do estudante atitudes ativas e reflexivas a partir de estruturas de trabalho interativas e construtivas.

Nesse sentido, evidenciamos que as arquiteturas pedagógicas de resolução de problemas contribuem para a formação de um sujeito ativo, que seja capaz de posicionarse criticamente, construir hipóteses e testá-las, enfim, que se mostre engajado na busca por seu conhecimento.

\section{Arquitetura Pedagógica de resolução de problemas a partir do Minecraft}

O Minecraft é um jogo digital de mundo aberto, onde o jogador pode construir cenários, de forma individual ou acompanhado de outras pessoas, utilizando blocos que se assemelham ao Lego. $\mathrm{O}$ jogo dispõe de um inventário com inúmeros recursos, onde o jogador pode criar construções como, casas, cidades, fazendas, castelos, enfim, construir mundos variados, de maneira infinita. O maior desafio a ser superado no jogo é o limite da criatividade do jogador, que poderá compactar ou então, expandir suas possibilidades de criação, conforme suas intenções e familiaridade com o jogo. As possibilidades de combinações que o inventário permite ao jogador são responsáveis pelo jogo nunca ser o mesmo para dois jogadores. Através de blocos de construção, blocos decorativos e ferramentas, são inúmeras as criações que o jogador pode executar.

Dentre algumas experiências de uso do Minecraft no contexto educacional, podemos citar, que em uma escola particular da Zona Sul de São Paulo (Knittel, Santana, Menuzzi e Pereira, 2017), os alunos estudaram os ecossistemas brasileiros e utilizaram o Minecraft para simular as paisagens no mundo virtual. Na mesma instituição, após visita ao estádio da Vila Belmiro, os alunos recriaram no Minecraft a construção, respeitando medidas de escalas, arquibancadas e projeto de iluminação do mesmo. Ainda nesse educandário, nas disciplinas de Ciências e Geografia, os alunos fizeram uma pesquisa acerca do processo de tratamento da água, representando, através do jogo, como o mesmo ocorria.

Em uma escola pública estadual de Diadema (Dias e Rosalen, 2014), o Minecraft foi utilizado em sua forma educacional, MinecraftEdu e, a partir dele, os alunos representaram as células estudadas durante as aulas de Ciências.

Com uma turma de $6^{\circ}$ ano, no Colégio Padre João Bagozzi (Torquato e Torquato, 2017), os alunos representaram os castelos medievais, buscando o entendimento de como o espaço desses castelos era utilizado pelos habitantes do local. 
VIII Congresso Brasileiro de Informática na Educação (CBIE 2019)

Anais dos Workshops do VIII Congresso Brasileiro de Informática na Educação (WCBIE 2019)

Em Araranguá (Custódio e Pozzebon, 2016), duas turmas de $3^{\circ}$ e $4^{\circ}$ ano do Ensino Fundamental aproveitaram do Minecraft para representar cenários e personagens de histórias infantis trabalhadas em sala de aula.

Evidenciamos que nas propostas pesquisadas e apresentadas acima a possibilidade de criação pelos alunos esteve ainda muito ligada a conteúdos escolares.

Assim, buscando o uso de arquiteturas pedagógicas em jogos digitais, este artigo apresentará um recorte de uma pesquisa realizada, na qual o objetivo do uso do jogo não se resume a representações e entendimento de conteúdos desenvolvidos em sala de aula. Ele propõe, em contrapartida, um desafio a ser enfrentado, para o qual não há receita e nada está pronto, no intuito de perseguir o raciocínio e pensamento da criança durante a resolução das situações apresentadas.

Nesse contexto, o aluno torna-se um sujeito ativo, que precisa pensar sobre a forma como resolverá o problema, avaliar suas possibilidades, fazer escolhas e planejar suas ações, no intuito de cumprir a tarefa que lhe foi proposta. Observaremos, no decorrer deste escrito, que em diversos momentos os alunos foram confrontados com desequilíbrios cognitivos, que por sua vez, provocaram regulações e reconstruções que permitiram um novo equilíbrio, em um patamar superior.

\section{Produção dos Dados}

Este artigo, apresenta um extrato de um estudo de caso, no qual participaram oito sujeitos, estudantes de uma Escola Pública Municipal de Farroupilha-RS, com idade entre 11 e 13 anos. Os objetivos da pesquisa estiveram expressos em compreender as potencialidades da inserção das Tecnologias Digitais no contexto educacional, além de acompanhar o percurso cognitivo de resolução de problemas desenvolvido pelas crianças, buscando identificar entre elas, algumas regularidades. Os resultados, com relação ao desenvolvido cognitivo, foram analisados tendo em vista as ideias expressas por Inhelder e Cellérier (1996) em seu livro "O desenrolar das descobertas da criança: um estudo sobre as microgêneses cognitivas", além de acompanhar os estudos desenvolvidos por Piaget (1985) em seu livro "O Possível e Necessário: a evolução dos possíveis na criança".

Sendo assim, os alunos foram convidados a resolver situações-problema no contexto do jogo Minecraft. Tais situações foram propostas pela pesquisadora, que acompanhou os sujeitos durante o processo de resolução. No contexto da metodologia de pesquisa qualitativa, o presente estudo de caso foi desenvolvido pela pesquisadora, que fez a leitura inicial dos problemas a serem resolvidos pelos sujeitos, propondo questionamentos, baseados no método clínico, no intuito de perseguir o pensamento da criança acerca das ações executadas.

Portanto, foram propostas às crianças quatro situações-problema, sendo as duas primeiras resolvidas de maneira individual, e as demais, em dupla. O critério para organização do modo de resolução, individual ou em dupla, foi pensado em virtude da complexidade dos desafios propostos.

Cabe destacar que, no intuito de facilitar a análise dos dados, as resoluções de problemas foram gravadas em vídeo para serem revisitadas pela pesquisadora em momento posterior, facilitando a análise dos dados e o acompanhamento dos detalhes do percurso. É importante mencionar que, os estudantes não possuíam limite de tempo para 
VIII Congresso Brasileiro de Informática na Educação (CBIE 2019)

Anais dos Workshops do VIII Congresso Brasileiro de Informática na Educação (WCBIE 2019)

a resolução dos desafios, sendo que, as filmagens eram encerradas quando o sujeito manifestava o término da solução. Além disso, é relevante esclarecer que cada aluno foi solicitado a resolver uma situação-problema por semana. $\mathrm{O}$ intuito era estabelecer um tempo considerável para cada estudante, além de buscar não os sobrecarregar na resolução de dois desafios de forma consecutiva. A produção dos dados foi consolidada entre os meses de abril e junho do ano de 2019.

\section{Situações-Problema Propostas}

Para elucidar a análise dos dados que segue, cabe ressaltar que as situações-problema de foram desenvolvidas pela pesquisadora tendo como inspiração algumas propostas apresentadas por Inhelder (1996) em suas pesquisas, além de buscar inspiração nos desafios desenvolvidos por Piaget (1985), em seu Livro "O Possível e o Necessário - a Evolução dos Possíveis na Criança". Parte-se da hipótese de que os níveis de dificuldade apresentado nas propostas de 1 a 4 sejam crescentes, sendo a de número 1 uma proposta mais fácil de resolução, e a 4, uma proposta que envolve estratégias mais complexas para ser resolvida.

No decorrer da análise dos dados, a pesquisadora esteve atenta aos estudos desenvolvidos por Inhelder (1996) e Piaget (1985) para buscar compor o percurso individual de cada sujeito, tendo em vista a representação do problema, a sequência de ações executada, bem como os esquemas selecionados por eles. Além disso, foram observadas as descobertas realizadas durante o percurso, buscando evidenciar momentos de desequilíbrios cognitivos, e condutas que indicassem o nível de construção dos possíveis dos sujeitos.

A seguir, apresentaremos as quatro propostas de resolução de problemas, para que o leitor possa acompanhar com mais tranquilidade a análise dos dados. A primeira tarefa, denominada "Bolo de Aniversário", resolvida de forma individual pelas crianças, consistia na busca de solução para o seguinte desafio: Aninha fará 8 anos na próxima semana e está organizando uma festa de aniversário. Na sua festa, não pode faltar um bolo para apagar as velinhas. Mas Aninha está muito indecisa, pois ela gosta de bolo de diferentes sabores: adora bolo de chocolate, mas também acha deliciosos os bolos de morango e uva. Aninha descobriu que na padaria que fica próxima a sua casa, são produzidos bolos de mais de um sabor, colocando sempre cada sabor em uma camada. Então, Aninha teve uma ideia: comprará um bolo de três camadas! Ela só precisa decidir a ordem dos sabores! Vamos ajudar Aninha a descobrir todas as formas diferentes que são possíveis de produzir seu bolo? Lembre-se que não podem ser construídos bolos com a ordem de camadas iguais!

$\mathrm{Na}$ sequência, ainda de forma individual, os alunos resolveram ao seguinte desafio, denominado "Organização da Fazenda": Seu Arnaldo possui muitos animais em sua fazenda, além de ter plantações de diferentes frutas e verduras. Ele adora suas ovelhas, mas ultimamente, eles estão comendo toda a sua plantação. Ele também gosta muito de suas vacas, mas eles também tem se alimentado de suas plantações. Seu Arnaldo precisa resolver essa situação, pois não quer se desfazer dos bichinhos que tanto gosta. Vamos ajudar seu Arnaldo a resolver esse problema? Se você fosse seu Arnaldo, o que faria para mudar essa situação na fazenda? 
Como terceiro desafio a ser resolvido, em duplas, os alunos deveriam chegar à resposta para a seguinte situação-problema, denominada "Canteiro de Flores": A floricultura de Seu Júlio está organizando uma reforma e para isso precisa reconstruir seus canteiros, colocando sempre, em cada um deles, uma unidade das espécies de flor: orquídeas azuis, roseiras, girassóis, violetas, margaridas e tulipas laranjas. Porém, como as flores são muito delicadas, algumas não podem ter contato direto com as outras, ou seja, não podem ser colocadas lado a lado, por correm o risco de trocarem de cor. Seu Júlio precisa estar atento a essas instruções na hora de construir seus canteiros para que as flores não sejam estragadas: as orquídeas azuis não podem estar ao lado das roseiras; os girassóis não podem estar ao lado das violetas e das margaridas; as tulipas laranjas não podem estar ao lado das margaridas e dos girassóis. Vamos ajudar Seu Júlio a reconstruir seus canteiros? Não se esqueça das regras que ele deve seguir. Construa o máximo de canteiros possíveis.

Já a última situação problema, intitulada “Transporte para o Celeiro”, propunha a resposta para o seguinte desafio: Em um cercado há dois animais e um alimento: um porco, uma galinha e uma maçã. Eles precisam ser transportados para um novo celeiro, observando a seguinte consideração: a maçã e a galinha não podem ficar sozinhas, no mesmo lugar, ao mesmo tempo, porque a galinha comerá a maçã. A maçã e o porco também não podem ficar sozinhos, no mesmo lugar, ao mesmo tempo, pois o porco também comerá a maçã. De que forma o fazendeiro poderá transportar os animais e elementos em segurança para o novo celeiro? Só pode ser transportado um item de cada vez no trajeto de ida, e de volta.

\section{Análise dos Resultados}

A seguir apresentaremos uma síntese dos resultados encontrados, buscando organizá-los na forma das regularidades identificadas durante a pesquisa.

Com relação à resolução da proposta Bolo de Aniversário, identificamos que a maioria dos alunos, ou seja, sete dos oito alunos participantes da pesquisa, referenciou uma representação inicial que indicava três bolos a construir, com a combinação dos sabores disponíveis. Findada a primeira etapa da resolução do problema e, tendo em vista a contra argumentação apresentada pela pesquisadora os alunos demonstraram um desequilíbrio cognitivo. Os escritos de Piaget, interpretados através das palavras de Montangero e Maurice-Naville (1998, p. 156), nos mostram que "as perturbações provocam um desequilíbrio (causa ou desencadeador da equilibração) que engendra regulações (meios pelos quais a equilibração se realiza). As regulações visam a compensar as perturbações, mas fazendo isso, geram novas construções". Nesse sentido, entendemos que a contra argumentação assumiu o papel de uma perturbação, um desafio a ser superado, onde, a partir de um processo de regulações, os sujeitos conseguiram estabelecer um novo equilíbrio, em um outro patamar, e com isso, identificaram novas formas possíveis de construir os bolos, chegando à solução final, expressa por seis bolos.
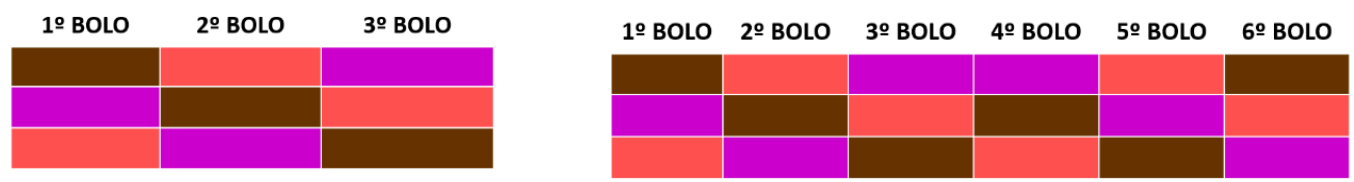

Figura 1: Representação da resolução do problema Bolo de Aniversário 
Também, com relação à primeira proposta, identificamos que os sujeitos não conseguiram explicar, em uma lei geral, como é que se resolve o problema. Essa premissa nos mostra que as ações realizadas estiveram mais diretamente ligadas ao fazer, ou seja, à ação dos sujeitos de forma analógica. Buscando subsídios nos escritos de Piaget (1977) percebemos que os sujeitos em questão ainda caminham em direção à tomada de consciência, visto que se encontram em um processo inicial, onde recorrem a esquemas isolados de assimilação. Nesta etapa, os sujeitos não combinam ações, pois não há uma antecipação e nem transitividade, o que acaba gerando uma acomodação momentânea, difícil de ser aplicada a outros contextos.

Dessa forma, foi possível identificar que a maioria dos sujeitos se encontra em um nível de construção dos possíveis engendrado em sucessões analógicas, onde as ações são desencadeadas uma a uma, e seguem uma ideia de ensaios. Os sujeitos relataram que os três primeiros bolos são mais fáceis de construir e, depois, os outros três, tem que ir observando, testando e construindo. Piaget (1985) destaca que nesse nível, os sujeitos estão atentos às observações, já que efetuam suas ações baseando-se em tentativas de acertos e erros.

$\mathrm{Na}$ sequência, ao acompanharmos a resolução do desafio "Organização da Fazenda" identificamos que os sujeitos elaboraram uma representação inicial do problema, encontrando formas de soluções muito semelhantes, mesmo que, nesse caso, o desafio proposto permitisse uma variedade de soluções, instigando a criação dos estudantes.

Os sujeitos pesquisados apresentaram como solução para este desafio a construção de cercas ou celeiros para prender os animais, referindo-se que já haviam visto construções semelhantes no sítio ou em sua casa. Atribuímos essas ações ao que Inhelder e Cellérier (1996) chamaram de esquemas familiares que se configuram “(...) à maneira de ideias pré-formadas, enquanto unidades epistêmicas e heurísticas constituídas e disponíveis para um sujeito que só teria de evocá-las ou aplicá-las diretamente (INHELDER E CELLÉRIER, 1996, p. 30)".

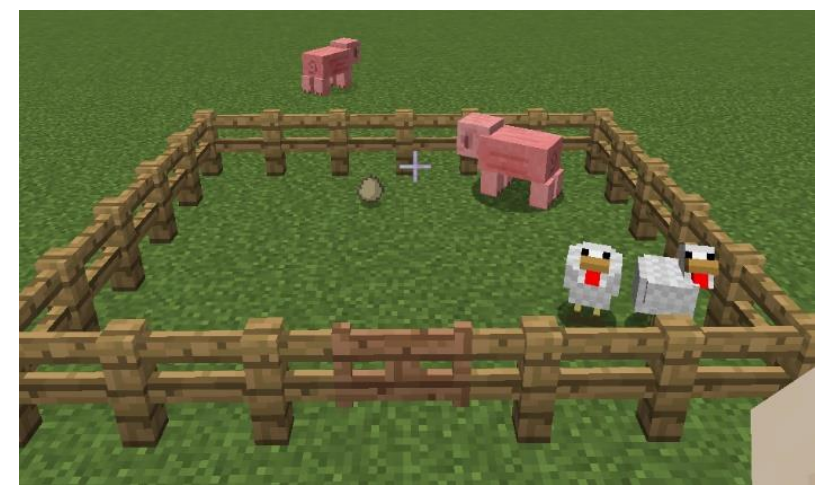

Figura 2: Exemplo de resolução do problema Organização da Fazenda (extraída da interface do Jogo Minecraft, criada por um dos alunos)

Identificamos, ainda, que os alunos controlaram suas ações durante a resolução do problema, executando melhorias em seus projetos. Ainda que essas não tenham sido antecipadas, foram concebidas a partir das ações já realizadas, evidenciando uma construção baseada em sucessões analógicas. Apenas um dos sujeitos vislumbrou mais possibilidades de construções, sem que necessitasse executá-las. Os demais concluíram que suas construções eram as únicas possíveis. 
Por fim, evidenciamos que durante a resolução do desafio "Organização da Fazenda", o erro apareceu como um obstáculo a ser superado. Afirmamos esta premissa, visto que, todos os alunos que se depararam com situação de fracasso, foram capazes de superar a posição de dificuldade, encontrando uma nova possibilidade que ressignificasse o seu processo, e proporcionasse a retomada de rumo da proposta.

Com relação à resolução do desafio dos "Canteiros de Flores", identificamos muitos aspectos teóricos em comum aos apresentados nos desafios anteriores. Inicialmente, tendo em vista o nível de dificuldade, que se tornou superior nesse desafio, observamos que os alunos não elaboraram uma representação inicial do problema, verbalizando, sem reflexão, o número de variações que achavam possíveis de serem construídas. Assim, as combinações de canteiros construídos variaram entre os sujeitos pesquisados, assim como a quantidade de canteiros que cada dupla considerou como solução para o seu problema.

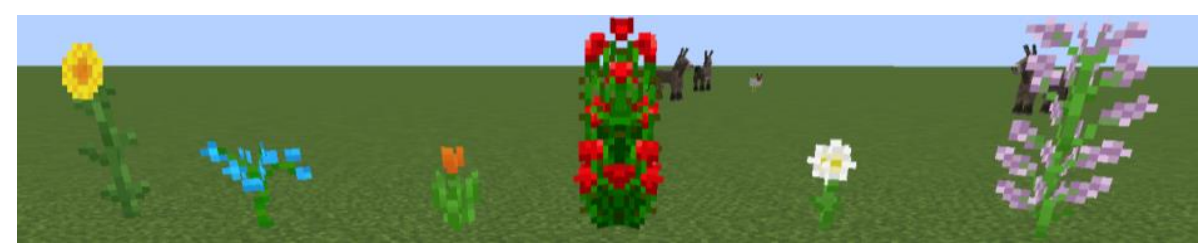

Figura 3: Representação da resolução do problema Canteiro de Flores (extraída da interface do Jogo Minecraft, criada por um dos alunos)

As construções dos canteiros ocorreram no desenrolar das ações e no seu controle, baseando-se, mais uma vez, em sucessões pautadas em tentativas (acertos e erros). Bem como no primeiro desafio, os alunos não deduziram uma regra que pudesse ser aplicada por eles e que pudesse ser usada para solucionar problemas semelhantes ou com variações no número de flores e de restrições. Esses fatos reforçam as formas de resolução por analogias observadas nos desafios anteriores, já que as ações foram executadas uma a uma, e que, as relações estabelecidas em um canteiro, por exemplo, não foram conservadas para os seguintes.

Entendemos, conforme Piaget (1985 p. 8) que na perspectiva da construção dos possíveis "um erro corrigido pode ser mais fecundo do que um sucesso imediato", visto que, durante a resolução do desafio, o erro se fez muito presente e, mais uma vez, apareceu como um desafio a ser superado, provocando modificações nos projetos desenvolvidos e, instigando a construção de mais canteiros.

Além disso, os sujeitos consideraram o trabalho em grupo como facilitador da resolução do problema, atribuindo a colaboração entre os pares como um aspecto essencial para a obtenção do êxito.

Ao analisarmos o percurso dos sujeitos no último desafio, "Transporte ao celeiro", evidenciamos as mesmas condutas descritas nas resoluções anteriores. Com relação a isso, podemos destacar as tentativas de descoberta da solução, sem uma representação inicial suficiente para orientar a solução e amparada por uma sucessão de ações, baseadas em acertos e erros. Ademais, as pseudoimpossibilidades se fazem muito presentes, durante o percurso de resolução e, em uma grande parte do desafio, acabam impedindo a visualização de uma solução possível pelos sujeitos. Por esse motivo, o erro se faz também muito presente e aparece como uma situação difícil de ser superada. Entendemos 
VIII Congresso Brasileiro de Informática na Educação (CBIE 2019)

Anais dos Workshops do VIII Congresso Brasileiro de Informática na Educação (WCBIE 2019)

esse fato, visto que a possibilidade de reversibilidade se coloca como uma limitação até que seja encontrada a solução do problema.

Em contrapartida, como no desafio anterior, os sujeitos consideraram o trabalho em grupo como facilitador da resolução do problema. Estabeleceram durante o percurso um diálogo com seus pares, no intuito de trocar ideias de transporte até o momento em que descobriram e efetivamente executaram o desafio proposto (solução: levar a maçã ao celeiro; voltar e buscar um dos animais; deixar o animal no celeiro e, ao mesmo tempo, transportar a maçã de volta para o cercado; em seguida, deixar a maçã no cercado, levando o animal que restou ao celeiro; por fim, retornar ao cercado, pegar a maçã e transportá-la ao celeiro).

\section{Síntese dos Resultados e Considerações Finais}

Apresentamos neste artigo uma experiência realizada a partir de uma arquitetura pedagógica usando um jogo digital. Evidenciamos, no desenvolvimento das soluções aos desafios, que a proposta de aplicação de metodologia ativa instigou os sujeitos a assumirem uma postura protagonista.

A interatividade vivenciada durante o jogo possibilitou as experimentações, a retomada das ações a partir dos erros e maior envolvimento dos alunos. No uso da arquitetura pedagógica de resolução de problemas, os alunos precisaram atentar para as características que estavam presentes no mundo virtual e que são semelhantes ao nosso mundo, bem como precisaram lidar com situações em que a mesma lógica da vida real não se traduziu para o cenário do jogo, levando-os a buscar novas soluções para problemas em um "micromundo" com possibilidades e restrições específicas.

Os resultados nos mostram que, apropriados das possibilidades inseridas na arquitetura pedagógica de resolução de problemas, os alunos foram capazes de vencer os desafios que lhe foram apresentados, realizando descobertas, investigando e avançando com relação à representação inicial que elaboraram para a situação-problema. Ainda conforme os estudos de Inhelder e Cellérier (1996), observamos que as crianças organizaram e executaram uma sequência de ações (controlada ora por suas hipóteses, ora pelo seu próprio fazer) que buscava uma coerência, enquanto caminhava em direção aos subobjetivos e objetivos a que se propunham. Destacamos ainda que esse percurso de descobertas, tendo em vista os aspectos cognitivos proporcionou momentos onde os sujeitos necessitaram compensar as perturbações e, deste modo, necessitaram reestabelecer o equilíbrio cognitivo em um novo patamar, produzindo assim, novidades cognitivas.

Além disso, o aspecto inovador oportunizado pelo uso da arquitetura pedagógica possibilitou um ambiente prazeroso de aprendizagens aos estudantes. Ao colocá-los em situações de conflitos cognitivos, onde a busca pela superação da dificuldade tinha a ideia de um desafio a ser superado, os sujeitos construíram conhecimentos de uma maneira lúdica e dinâmica, no trabalho de forma individual ou em pares.

Por fim, tendo em vista os resultados analisados, entendemos que a arquitetura pedagógica de resolução de problemas em um jogo digital abordada neste artigo apresenta potencial que permite sua aplicação a outros contextos e situações, visto que, contribui para a aprendizagem dos estudantes, transformando seus processos cognitivos através de 
VIII Congresso Brasileiro de Informática na Educação (CBIE 2019)

Anais dos Workshops do VIII Congresso Brasileiro de Informática na Educação (WCBIE 2019)

uma metodologia ativa, que insere o aluno em uma postura de protagonista de suas descobertas.

"O presente trabalho foi realizado com apoio da Coordenação de Aperfeiçoamento de Pessoal de Nível Superior - Brasil (CAPES) - Código de Financiamento 001".

\section{Referências}

Aragon, R.; Menezes, C. S.; Ziede, M. L.; Charczuk, S. B. "Arquiteturas pedagógicas para a aprendizagem em rede no contexto do seminário integrador". CINTED UFRGS. v. 11- n² 2 ; novembro, 2013.

Carvalho, M. J. S.; Nevado, R. A.; Menezes, C. S. "Arquiteturas pedagógicas para educação a distância". Anais - XVI Simpósio Brasileiro de Informática na Educação, v.1, 2005 .

Custódio, R. C. de F. e; Pozzebon, E. "Minecraft: um jogo? Um mundo? Uma estratégia de ensino?” XV SBGames. São Paulo: SP - Setembro, 2016. p. 1157-1160.

Dalpiáz, M. M.; Menezes, C. S.; Nevado, R. A. "Arquiteturas pedagógicas para a construção colaborativa de conceituações”. Anais do CSBC. Workshop de Informática na Escola. Bento Gonçalves, 2009.

Dias, N. F.; Rosalen, M. "Minecraft: uma estratégia de ensino para aprender mais jogando". Encontro de Pesquisadores em Educação a Distância (ENPED). São Carlos: São Paulo, 2014.

Inhelder, B.; Cellérier, G. "O desenrolas das descobertas na criança: pesquisa acerca das microgêneses cognitivas”. Tradução: Eunice Gruman - Porto Alegre: Artes Médicas, 1996.

Knitell, T.; Santana, L.; Menuzzi, M.; Pereira, M. "Minecraft: experiências de sucesso dentro e fora da sala de aula". XVI SBGames. Curitiba: PR, Novembro-2017. p. 789795.

Maraschin, C.; Axt, M. Acoplamento Tecnológico e Cognição. In: Vigneron, J.; Oliveira, V. B. (org). "Sala de aula e Tecnologias". São Bernardo do Campo: Universidade Metodista de São Paulo, 2005. pp. 39-51.

Montangero, J.; Maurice-Naville, D. "Piaget ou a inteligência em evolução". Porto Alegre: ArtMed, 1998.

Piaget, J. "A tomada de consciência". São Paulo: Edições Melhoramentos, 1977. Tradução: Edson Braga de Souza.

J. O possível e o necessário: a evolução dos possíveis na criança. Tradução: Bernardina Machado de Albuquerque. Porto Alegre: Artes Médicas, 1985.

Savi, R; Ubricht, V. R. "Jogos digitais educacionais: benefícios e desafios". Revista Novas Tecnologias na Educação. CINTED-UFRGS. Volume 6, Fascículo 2. (2008).

Torquato, R. A.; Torquato, N. M. M. "Maquetes Virtuais: o uso pedagógico do Minecraft na disciplina de História nos finais do ensino fundamental". Revista Redin. v. 6 No 1. Outubro, 2017. 